\title{
Functional abilities after stroke: measurement, natural history and prognosis
}

\author{
DERICK T WADE, RICHARD LANGTON HEWER \\ From the Bristol Stroke Unit, Department of Neurology, Frenchay Hospital, Bristol, UK
}

SUMMARY Actual functional performance of 976 acute stroke patients was assessed using the Barthel index: the data were analysed to determine the frequency of disability after stroke, the validity of the Barthel index, and the recovery seen. At 6 months, over $45 \%$ of survivors were functionally independent. Validity of the Barthel index was confirmed: it related as expected with motor loss and factor analysis showed a single major factor. The items of the Barthel index form an hierarchical scale. There was some recovery between 3 weeks and 6 months in almost all patients: the major prognostic factors were urinary incontinence, functional ability, sitting balance and age.

Stroke accounts for nearly $5 \%$ of National Health Service expenditure in Britain, ${ }^{1}$ and is the fourth most expensive disease to the economy of the United States, after motor vehicle injuries, cancer and ischaemic heart disease. ${ }^{2}$ Much of the cost of stroke probably relates to the physical disability which determines time in hospital more than any need for prolonged investigation or treatment. However, there is little detailed information about the epidemiology of stroke-induced disability, and only recently has prognosis for functional recovery attracted attention.

Four studies based upon community surveys ${ }^{3-6}$ have reported on disability after stroke, and suggest that $60 \%-75 \%$ of survivors are totally independent, and $3 \%-9 \%$ totally dependent in self-care. These studies included patients who had not been admitted to hospital but gave little detail about the actual disabilities.

We have conducted a community survey of acute stroke emphasising self-care functions and attempting to assess the frequency of dependence in self-care activities. Analysis has been conducted to establish the validity of the Barthel Activity of Daily Living scale; the order of recovery of function; and the predictability of outcome soon after stroke.

\section{Patients and methods}

In the 28 months between 1 March 1981 and 30 June 1983, we recorded every acute stroke in a population of 215,000

Address for reprint requests: Dr DT Wade, Frenchay Hospital, Bristol BS16 1LE, UK.

Received 25 October 1985 and in revised form 7 January 1986. Accepted 13 January 1986 people registered with 96 general practitioners (family doctors) in Frenchay Health District, Bristol, England. The register $^{7}$ included all strokes, whether first or recurrent, mild or severe. We attempted to include patients who were not admitted to hospital. Patients who had an additional stroke in the first 6 months after the index stroke were not reregistered but 17 patients had later recurrences and were registered again. Nine hundred and seventy-six patients were registered, including $249(26 \%)$ who were never admitted to hospital in the first 6 months after stroke.

Stroke was a clinical diagnosis based on the WHO definition ${ }^{3}$ no routine investigations were required. Those later found to have another diagnosis were withdrawn. The diagnosis was confirmed by a neurologist's examination (DW) in $713(73 \%)$ of cases; in those who died before examination or were notified late, the diagnosis was confirmed by personal examination of available hospital notes. Surviving patients were seen as soon as possible after notification, then at 3 weeks and 6 months post-stroke.

Functional ability was measured using the Barthel Activity of Daily Living (ADL) index ${ }^{8}$ (table 1 ). This scale gives a score between 0 and 20 in one point increments (usually it is scored as 0 to 100 in 5 point increments, but this gives an exaggerated impression of accuracy). The top score of 20 implies functional independence, not necessarily normality. Information about function was recorded for the 24 hours before the assessment, and was taken from the best available source (for example, nurses, relatives, the patient). Patients were not asked to demonstrate ability on each item. No patient was "unassessable"; comatose patients were automatically given a score of 0 even if they had not yet been incontinent of faeces. Otherwise, we simply recorded a patient's actual function, whatever the reason for any disability noted, and not potential functional ability which may not be the same. 9 Motor loss was assessed using the Motricity Index ${ }^{10}$ that gives a score from 0 (total paralysis) to 100 (normal), and mental function (IQ) was measured with Raven's coloured progressive matrices, ${ }^{11}$ a non-verbal test for which normal data are available for the elderly. 
Table 1 The Barthel Activities of Daily Living scale (AfterMahoney and Barthel, 1965)

\begin{tabular}{|c|c|}
\hline Item & Categories \\
\hline Bowels & $\begin{array}{l}0=\text { incontinent } \\
1=\text { occasional accident } \\
2=\text { continent }\end{array}$ \\
\hline Bladder & $\begin{array}{l}0=\text { incontinent/catheterised } \& \text { unable to manage } \\
1=\text { occasional accident } \\
2=\text { continent }\end{array}$ \\
\hline Grooming & $\begin{array}{l}0=\text { needs help } \\
1=\text { independent for face/hair/teeth/shaving }\end{array}$ \\
\hline Toilet use & $\begin{array}{l}0=\text { dependent } \\
1=\text { needs some help } \\
2=\text { independent }\end{array}$ \\
\hline Feeding & $\begin{array}{l}0=\text { dependent } \\
1=\text { needs help e.g. cutting, spreading butter } \\
2=\text { independent in all actions }\end{array}$ \\
\hline $\begin{array}{l}\text { Transfer } \\
\text { (bed-chair) }\end{array}$ & $\begin{array}{l}0=\text { unable } \\
1=\text { major help, can sit } \\
2=\text { minor help (verbal or physical) } \\
3=\text { independent }\end{array}$ \\
\hline Walking & $\begin{array}{l}0=\text { unable } \\
1=\text { independent in wheelchair } \\
2=\text { walks with help of person (verbal/physical) } \\
3=\text { independent (may use aid) }\end{array}$ \\
\hline Dressing & $\begin{array}{l}0=\text { dependent } \\
1=\text { needs help, but does half } \\
2=\text { independent (including buttons/zips/laces) }\end{array}$ \\
\hline Stairs & $\begin{array}{l}0=\text { unable } \\
1=\text { needs help (verbal/physical) } \\
2=\text { independent }\end{array}$ \\
\hline Bathing & $\begin{array}{l}0=\text { dependent } \\
1=\text { independent }\end{array}$ \\
\hline
\end{tabular}

Two methods were used to investigate the structure of the scale. First, the extent to which the items form a coherent group was determined using the technique of factor analysis with varimax rotation. ${ }^{12}$ Second, the abilities of all patients were ranked to discover whether the items formed an hierarchical scale. Patients scoring 20 or $\mathbf{0}$ were excluded, as they clearly passed or failed every test. For each level, we noted whether the patient passed or failed that level. For example, a fully continent patient would pass both "occasional accident" and "fully continent", whereas someone needing help with buttons would pass "needs help" but fail "independent" in respect of dressing. This gave 20 pass/fail items for each patient.

The results relate solely to patients who were actually seen, because only demographic and historic data were abstracted from hospital notes, not clinical information. The phrase "Initial assessment" refers to the 545 patients seen within 7 days of the stroke: 168 patients were first seen later than 7 days.

\section{Results}

Table 2 records the numbers of patients independent. Patients were arbitrarily divided into five groups according to their score: 0-4 for "very severely disabled"; 5-9 "severely"; 10-14 "moderately"; 15-19 "mildly disabled"; and 20, independent. At 3 weeks and 6 months over $90 \%$ of all known survivors were seen (table 2). Twelve percent of those seen within 7 days had no measurable disability, and at 6 months $47 \%$ of survivors were totally independent for all ADL activities.

\section{Validity}

The extent to which this scale related to other measures was investigated by calculating the correlation coefficients between the total ADL score and the Motricity Index arm, leg and total scores, using the data relating to patients seen at 3 weeks. The coefficients $(\mathrm{r})$ were $+0.729($ Arm $),+0.751(\mathrm{Leg})$ and +0.774 (Total), all statistically significant $(p<$ $0.001)$.

The results of factor analysis were similar for all three points (table 3). At each point more factors could be extracted, but none accounted for more than $5 \%$ of total variance. The high "communality" for

Table 2 Functional independence after stroke

\begin{tabular}{|c|c|c|c|}
\hline Time post-stroke & 0-7 days & 3 weeks & 6 months \\
\hline $\begin{array}{l}\text { Number alive } \\
\text { Number assessed } \\
\text { Bowels - continent } \\
\text { Urine - continent } \\
\text { Grooming } \\
\text { Toilet use } \\
\text { Feeding } \\
\text { Transfer } \\
\text { Walking } \\
\text { Dressing } \\
\text { Stairs } \\
\text { Bathing }\end{array}$ & $\begin{array}{l}976 \\
531=100 \% \\
368(69 \%) \\
300(56 \%) \\
236(44 \%) \\
170(32 \%) \\
171(32 \%) \\
159(30 \%) \\
145(27 \%) \\
111(21 \%) \\
106(20 \%) \\
75(14 \%)\end{array}$ & $\begin{array}{l}626 \\
572=100 \% \\
495(87 \%) \\
437(76 \%) \\
419(73 \%) \\
350(61 \%) \\
352(62 \%) \\
333(58 \%) \\
346(60 \%) \\
280(49 \%) \\
268(47 \%) \\
198(35 \%)\end{array}$ & $\begin{array}{l}544 \\
494=100 \% \\
462(93 \%) \\
438(89 \%) \\
429(87 \%) \\
393(80 \%) \\
379(77 \%) \\
403(81 \%) \\
417(85 \%) \\
340(69 \%) \\
323(65 \%) \\
251(51 \%)\end{array}$ \\
\hline $\begin{array}{l}\text { Barthel scores: } \\
0-4 \text { (v severe) } \\
\text { 5-9 (severe) } \\
\text { 10-14 (moderate) } \\
15-19 \text { (mild) } \\
20 \text { (independent) } \\
\text { Mean (SD) } \\
\text { Range } \\
\text { First quartile } \\
\text { Median } \\
\text { Third quartile }\end{array}$ & $\begin{array}{l}201(38 \%) \\
104(20 \%) \\
80(15 \%) \\
82(15 \%) \\
64(12 \%) \\
8 \cdot 6(7 \cdot 3) \\
0-20 \\
1 \\
7 \\
16\end{array}$ & $\begin{array}{c}75(13 \%) \\
77(13 \%) \\
84(15 \%) \\
158(28 \%) \\
178(31 \%) \\
13.9(6 \cdot 7) \\
0-20 \\
9 \\
17 \\
20\end{array}$ & $\begin{array}{l}21(4 \%) \\
25(5 \%) \\
57(12 \%) \\
160(32 \%) \\
231(47 \%) \\
16.9(4 \cdot 8) \\
0-20 \\
16 \\
19 \\
20\end{array}$ \\
\hline
\end{tabular}


Table 3 Factor analysis of Barthel items at 3 weeks

\begin{tabular}{|c|c|c|c|}
\hline & \multicolumn{3}{|l|}{$n=572$} \\
\hline & Communality & V Factor 1 & Factor 2 \\
\hline $\begin{array}{l}\text { Percent variance } \\
\text { Factor loadings: }\end{array}$ & & $68 \%$ & $9 \%$ \\
\hline Bowels - continent & 0.76 & 0.86 & $-0 \cdot 14$ \\
\hline Urine - continent & 0.76 & 0.82 & $-0 \cdot 31$ \\
\hline Grooming & 0.69 & 0.72 & -0.42 \\
\hline Feeding & 0.71 & 0.72 & -0.47 \\
\hline Transfer & 0.84 & $0 \cdot 70$ & -0.58 \\
\hline Toilet use & 0.85 & 0.55 & -0.74 \\
\hline Walking & 0.83 & 0.52 & -0.75 \\
\hline Dressing & 0.86 & 0.51 & -0.77 \\
\hline Stairs & 0.82 & 0.28 & -0.86 \\
\hline Bathing & 0.65 & 0.15 & -0.47 \\
\hline
\end{tabular}

each item (never falling below $0 \cdot 65$ ) shows that each item was related strongly with all others. One major factor (grouping) accounted for two thirds of the total variance. These results strongly supported the validity of the Barthel index.

\section{Hierarchy of items}

If abilities were random, then there should have been roughly equal numbers independent in each activity. This was not so (table 4 ); at 3 weeks, $50 \%$ of patients scoring between 1 and 19 could groom alone but only $14 \%$ could dress alone. There was a clear hierarchy among the tests; bathing alone was the most difficult. The hierarchy was not inviolate: $3 \%$ of those scoring 19 or less could bathe alone, and in those cases other items must have been more difficult. Nevertheless, $25 \%$ or more conformed precisely, and over $75 \%$ were within 1 item of the hierarchy (table 5), indicating that any two patients having the same score were likely to have had an identical or closely similar pattern of disabilities.

\section{Recovery and prognosis}

The extent of recovery of function was studied in the 531 patients seen within 7 days of onset. Taking the five groups shown in table 1 , outcome was assessed at 6 months (table 6). A bad initial ADL functional state was associated with an increased mortality and less good function at 6 months. Considering only patients seen within 7 days of the stroke, who survived 6 months, and who had results from each time point, we calculated mean scores for four groups of patients, divided according to initial severity (fig). The results were analysed with the Wilcoxon signed ranks test for repeated measures, and all changes were significant at $\mathrm{p}<0.01$ except for the non-significant deterioration seen between 3 weeks and 6 months in the mildly disabled group.

The prognostic factors relating to recovery were sought by multiple regression analysis with the Wherry-Doolittle technique of test selection. ${ }^{13}$ The outcome studied was the Barthel score at 6 months. The items included from the early assessments were: Barthel score; urine incontinence; arm, leg and total Motricity scores; visual fields; cognitive function (ability to copy a "Greek Cross"); sitting balance; IQ (Raven's matrices); loss of consciousness at onset; and age in years at time of stroke. Analysis was restricted to those with some disability (that is Barthel score $0-19)$, as those already independent were unlikely to show any change. Full information was available on 279 such patients seen within 7 days and 243 patients seen at 3 weeks.

For the 279 patients seen within 7 days and having

Table 4 Order of recovery of independence, partial or complete (only those scoring 1-19)

\begin{tabular}{|c|c|c|c|}
\hline \multirow[b]{2}{*}{ Items } & \multirow{2}{*}{$\frac{0-7 \text { days }}{\text { Order } n=357}$} & \multirow{2}{*}{$\frac{3 \text { weeks }}{\text { Order } n=345}$} & \multirow{2}{*}{$\frac{6 \text { months }}{\text { Order } n=256}$} \\
\hline & & & \\
\hline $\begin{array}{l}\text { Bowels, accident } \\
\text { Feeding, with help } \\
\text { Transfer, much help } \\
\text { Bowels, continent } \\
\text { Urine, accident } \\
\text { Transfer, little help } \\
\text { Toilet, helped } \\
\text { Urine, continent } \\
\text { Grooming alone } \\
\text { Dresses, helped } \\
\text { Wheelchair } \\
\text { Walks with help } \\
\text { Feeds alone } \\
\text { Toilet alone } \\
\text { Walks alone } \\
\text { Transfers alone } \\
\text { Stairs, helped } \\
\text { Dresses alone } \\
\text { Stairs alone } \\
\text { Bathing alone }\end{array}$ & $\begin{array}{l}\text { 1. } 337(94 \%) \\
\text { 2. } 336(94 \%) \\
\text { 3. } 332(93 \%) \\
\text { 4. } 317(89 \%) \\
\text { 5. } 305(85 \%) \\
\text { 6. } 271(76 \%) \\
\text { 7. } 262(73 \%) \\
\text { 8. } 259(73 \%) \\
\text { 9. } 241(68 \%) \\
\text { 10. } 238(67 \%) \\
11.238(67 \%) \\
12.236(66 \%) \\
13.174(49 \%) \\
14.172(48 \%) \\
15.168(47 \%) \\
16.156(44 \%) \\
17.131(37 \%) \\
18.102(29 \%) \\
\text { 19. } 90(25 \%) \\
20.20(6 \%)\end{array}$ & $\begin{array}{l}\text { 1. } 332(96 \%) \\
\text { 5. } 272(79 \%) \\
\text { 4. } 274(79 \%) \\
\text { 2. } 304(88 \%) \\
\text { 3. } 277(80 \%) \\
\text { 7. } 200(58 \%) \\
\text { 8. } 199(58 \%) \\
\text { 6. } 236(68 \%) \\
\text { 9. } 172(50 \%) \\
\text { 11. } 156(45 \%) \\
\text { 10. } 158(46 \%) \\
\text { 12. } 154(45 \%) \\
\text { 13. } 107(31 \%) \\
14.106(31 \%) \\
16.81(23 \%) \\
15.95(28 \%) \\
\text { 17. } 76(22 \%) \\
\text { 18. } 47(14 \%) \\
\text { 19. } 42(12 \%) \\
\text { 20. } 11(3 \%)\end{array}$ & $\begin{array}{r}\text { 3. } 245(96 \%) \\
1.252(98 \%) \\
\text { 2. } 250(98 \%) \\
\text { 4. } 231(90 \%) \\
\text { 6. } 223(87 \%) \\
4.231(90 \%) \\
\text { 8. } 217(85 \%) \\
\text { 10. } 207(81 \%) \\
\text { 12. } 198(77 \%) \\
\text { 11. } 204(80 \%) \\
\text { 7. } 222(87 \%) \\
\text { 9. } 213(83 \%) \\
\text { 16. } 148(58 \%) \\
15.162(63 \%) \\
13.186(73 \%) \\
14.172(67 \%) \\
17.131(51 \%) \\
18.109(43 \%) \\
\text { 19. } 92(36 \%) \\
\text { 20. } 20(8 \%)\end{array}$ \\
\hline
\end{tabular}


Table 5 Concordance between total score and place on hierarchy shown in table 4 (only patients scoring 1-19)

\begin{tabular}{lccc}
\hline Time & Initial & 3 weeks & 6 months \\
\hline Number & 345 & 357 & 256 \\
$\begin{array}{l}\text { Errors (number of points): } \\
0 \text { (completely correct) }\end{array}$ & $86(25 \%)$ & $88(25 \%)$ & $75(29 \%)$ \\
$+1-1$ & $179(52 \%)$ & $186(52 \%)$ & $122(48 \%)$ \\
$+1-2$ & $60(17 \%)$ & $68(19 \%)$ & $47(18 \%)$ \\
$+1-3-6$ & $20(6 \%)$ & $15(4 \%)$ & $12(5 \%)$ \\
\hline
\end{tabular}

Table 6 Prognosis, according to initial severity

\begin{tabular}{|c|c|c|c|c|c|}
\hline \multirow[b]{2}{*}{ Initial score } & \multicolumn{5}{|c|}{532 patients, outcome at 6 months } \\
\hline & $0-4$ & $5-9$ & $10-14$ & $15-19$ & 20 \\
\hline $\begin{array}{l}\text { Number } \\
\text { Died } \\
\text { Alive, lost to FU } \\
\text { Alive and assessed }\end{array}$ & $\begin{array}{l}202 \\
133(66 \%) \\
2 \\
67(33 \%)\end{array}$ & $\begin{array}{l}104 \\
24(23 \%) \\
1 \\
79(76 \%)\end{array}$ & $\begin{array}{l}80 \\
13(16 \%) \\
6 \\
61(76 \%)\end{array}$ & $\begin{array}{l}82 \\
9(11 \%) \\
4 \\
69(84 \%)\end{array}$ & $\begin{array}{l}64 \\
2(3 \%) \\
0 \\
62(97 \%)\end{array}$ \\
\hline $\begin{array}{l}\text { Barthel score at } 6 \text { months: } \\
\text { Total assessed } \\
0-4 \\
5-9 \\
10-14 \\
15-19 \\
20\end{array}$ & $\begin{array}{l}67 \\
9(13 \%) \\
9(13 \%) \\
18(27 \%) \\
24(36 \%) \\
7(11 \%)\end{array}$ & $\begin{array}{l}79 \\
5(6 \%) \\
4(5 \%) \\
23(29 \%) \\
34(43 \%) \\
13(17 \%)\end{array}$ & $\begin{array}{l}61 \\
1(2 \%) \\
1(2 \%) \\
3(5 \%) \\
22(36 \%) \\
34(55 \%)\end{array}$ & $\begin{array}{l}69 \\
3(4 \%) \\
1(2 \%) \\
3(4 \%) \\
24(35 \%) \\
38(55 \%)\end{array}$ & $\begin{array}{l}62 \\
0 \\
0 \\
0 \\
7(11 \%) \\
55(89 \%)\end{array}$ \\
\hline
\end{tabular}

some disability at that time, four items were selected. The items (and their beta values) were: urinary incontinence $(+0.289)$; Barthel score at the time $(+0.283)$; age $(-0 \cdot 181)$; and sitting balance $(-0 \cdot 099)$. The equation generated was:

Barthel score at 6 months $=1.872 \times$ urine incontinence $+0.248 \times$ initial Barthel score -0.098 $\times$ age $-0.484 \times$ sitting balance +18.68 .

This equation had a multiple correlation coefficient (R) of 0.511 and accounted for $26 \%$ of the variance

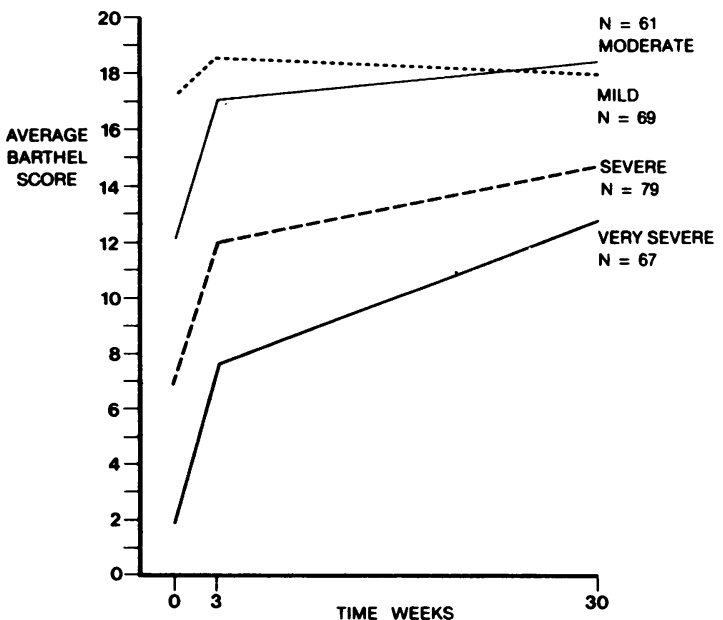

Fig 1 Graph showing change in average Barthel score after stroke, patients being divided according to initial severity. seen at 6 months. The arithmetic signs implied that those who did better were continent, had a higher initial Barthel score, were younger and had a worse sitting balance. This apparently bizarre finding (that the worse sitting balance was the better recovery) arises because information about sitting balance added to the predictive accuracy, and simply illustrates the limitation of mathematical analytic techniques. The success of the equation was tested by applying it to the same group of patients: $183(66 \%)$ either were predicted correctly or actually made a better recovery than predicted; $56(20 \%)$ scored 3 or more points less than predicted; and the remaining 40 $(14 \%)$ were within 2 points.

For the 243 patients seen at 3 weeks and still having some disability, five items were selected. The items (and their beta values) were: Barthel score at the time $(+0.211)$; urine incontinence $(+0 \cdot 169)$; arm Motricity score $(+0 \cdot 164)$; age $(-0 \cdot 178)$; and IQ $(+0 \cdot 104)$. The equation generated was:

Barthel score at 6 months $=+0.199 \times$ Barthel score at 3 weeks $+1.235 \times$ urine incontinence $+0.023 \times$ arm 'Motricity' score $-0.097 \times$ age $+0.019 \times \mathrm{IQ}+14.79$.

This equation had a multiple correlation coefficient (R) of 0.54 , accounting for $29 \%$ of the variance seen at 6 months. The arithmetic signs implied that those who did better had a higher 3 week Barthel score, were continent, had better motor power in the arm, had a higher IQ measured at 3 weeks and were younger. When the equation was applied to the same 
Table 7 Prediction of outcome; items and their coding

\begin{tabular}{ll}
\hline 1. Urinary incontinence & $\begin{array}{l}0=\text { incontinent (inc. coma) } \\
1=\text { occasional accident }\end{array}$ \\
& $2=$ continent \\
2. Barthel score & In years, at time of stroke \\
3. Age & Measured IQ, 53-130, except: \\
4. IQ (Raven's matrices) & $40=$ unassessable \\
5. Sitting balance & $0=$ unable to balance \\
& $1=$ needs help of person \\
& $2=$ needs to support self \\
& $3=$ balances unaided \\
& $0-100$, Motricity score \\
\hline
\end{tabular}

patients, $153(63 \%)$ did as well as or better than predicted, $46(19 \%)$ were 3 or more points worse than predicted and $44(18 \%)$ were predicted to be 1-2 points better than achieved.

\section{Discussion}

This study, based upon a large unselected community sample of stroke patients, gives further evidence that the Barthel index is a valid scale for studying function in stroke patients. We confirmed many findings made on smaller selected groups of patients. Urinary incontinence after stroke was a major prognostic indicator but, even together with some limited additional information, $20 \%$ of patients had an outcome worse than predicted.

In a study of this kind, the sample of patients should be representative of all stroke patients. Only $545(56 \%)$ of our patients were seen within 7 days of onset, but at later follow up times over $90 \%$ of all survivors were seen. Most of those missed were late "notifications" picked up from hospital discharge records. Twenty-six percent of all patients were never admitted within the first 6 months, and $24 \%$ of them were severely disabled. ${ }^{7}$ Home care is not unique to the UK; it has been recorded in the USA, ${ }^{14}$ Denmark, ${ }^{6}$ and throughout Europe. ${ }^{3}$

The use of Activity of Daily Living (ADL) scales in studies on disabling diseases has been discussed, ${ }^{15}$ but few studies have critically examined the data recorded using such scales. One study showed that giving arbitrary weights to apparently disparate items did not affect the scale. ${ }^{16}$ Analysis of a scale designed for use in studies on multiple sclerosis found a core of traditional ADL activities, with some non-ADL items being obviously separate. ${ }^{17}$ Another aspect of a scale is the extent to which a particular score can be related to a patient's particular abilities. Do all patients scoring 10 pass and fail the same tests, or do they have very different patterns of disabilities?

Although many ADL scales have been used in stroke research, ${ }^{18}$. the Barthel scale is probably the "best-buy", 19 and is now probably the most widely used ADL scale. Validity has been established ${ }^{20}$ before and our findings confirm its validity, but no formal tests of reliability have been reported. All ADL scales lack sensitivity at the upper range of ability. ${ }^{21}$ There is a discrepancy between what patients can do and what they do do, ${ }^{9}$ and we concentrated on actual functions as this is more relevant clinically.

The analyses of the items of the Barthel scale lend support to its use as a summed scale. Factor analysis confirmed that one major factor accounted for $68 \%$ of the variance. It is likely that abilities recover in a consistent order (for example feeding independently before dressing independently), as has been demonstrated before, ${ }^{22}$ and that equivalent scores imply similar disabilities.

Our data for recovery are similar to those recorded before. ${ }^{21}$ Recovery was fastest in the first few weeks, but change was also seen between 3 weeks and 6 months in most patients. We cannot say at what point recovery ceased. Ability to dress unaided is relatively late in recovering, as has been noted before. ${ }^{23}$ The amount of residual disability at 6 months was also similar to that reported by others, ${ }^{3-6}$ although ours is the first study to give detailed information.

Our investigation of prognosis confirms previous findings, ${ }^{2425}$ highlighting the importance of urinary incontinence. The initial Barthel score is an important prognostic factor for both recovery of function and for survival. Age has been considered important, ${ }^{25}$ but direct study of associations between age and stroke severity or outcome failed to indicate any significant associations. ${ }^{26}$ Sitting balance or trunk control has also been considered important, ${ }^{24}$ but in our study it had a negative influence; those with good control had worse outcome, perhaps an artefact arising from the use of multiple regression: poor trunk control itself cannot imply good prognosis. Arm function and IQ were important at 3 weeks, as shown by others. ${ }^{24} 2527$

We conclude the following: (1) Many patients have complete functional independence 6 months after an acute stroke. The exact proportion depends upon the function studied, but is never less than $50 \%$. (2) Initial severity determines both the likelihood of death and the extent of recovery. More accurate prognosis arises from considering urinary incontinence, age, arm function and IQ. (3) The Barthel ADL scale is a satisfactory measure of function after stroke.

We gratefully acknowledge the complete cooperation of all the physicians whose patients we studied, especially the general practitioners of Frenchay; the Department of Health and Social Security and Avon Joint Funding Committee for funding the research; Miss Caroline White and Mrs Vicky Wood for their help; and the patients for their enthusiastic cooperation. 


\section{References}

1 Wade DT, Wood VA, Langton Hewer R. Use of hospital resources by acute stroke patients. $J R$ Coll Phys Lond 1985;19:48-52.

2 Hartunian NS, Smart CN, Thompson MS. The incidence and economic costs of cancer, motor vehicle injuries, coronary heart disease, and stroke: a comparative analysis. Am $J$ Public Health 1980;70: 1249-60.

3 Aho K, Harmsen P, Hatano S, Marquardsen J, Smirnov V, Strasser T. Cerebrovascular disease in the community: results of a WHO Collaborative Study. Bull WHO 1980;58:113-30.

4 Weddell JM, Beresford SAA. Planning for Stroke Patients: a four year Descriptive Study of Home and Hospital Care. Department of Health and Social Security. HMSO London. 1979.

5 Gresham GE, Phillips TF, Wolf PA, McNamara PM, Kannel WB, Dawber TR. Epidemiologic profile of long-term stroke disability: the Framingham study. Arch Phys Med Rehabil 1979;60:487-91.

6 Sorensen PS, Boysen G, Jensen G, Schnohr P. Prevalence of stroke in a district of Copenhagen. Acta Neurol Scand 1982;66:68-81.

7 Wade DT, Langton Hewer R, Skilbeck CE, Bainton D, Burns-Cox CR. Home care for acute stroke: results of a controlled trial. Lancet 1985;1:323-6.

8 Mahoney FI, Barthel DW. Functional evaluation: the Barthel index. Maryland State Med J 1965;14:61-5.

9 Andrews K, Stewart J. Stroke recovery: he can but does he? Rheumatol Rehabil 1979;18:43-8.

10 Demeurisse G, Demol O, Robaye E. Motor evaluation in vascular hemiplegia. Eur Neurol 1980;19:382-9.

11 Raven JC. Guide to Using the Coloured Progressive Matrices. London: Lewis 1965.

12 Nunnally JC. Psychometric Theory. New York: McGraw-Hill 1978:112-3, and Chs 10-11.

13 Garrett HE. Statistics in psychology and education. Ch 16 London: Longmans, 1958.

14 Peacock PB, Riley CP, Lampton TD, Raffel SS, Walker
JS. The Birmingham stroke epidemiology and rehabilitation study. In: Stewart GT (ed) Trends in Epidemiology Springfield: Charles C Thomas, 1972:231-345.

15 Halpern AS, Fuhrer MJ, (eds). Functional Assessment in Rehabilitation. Baltimore: Paul H Brookes, 1984.

16 Bebbington AC. Scaling Indices of Disablement. Br J Prev Soc Med 1977;31:122-6.

17 Minderhoud JM, Dassel H, Prange AJA. Proposal for summing the incapacity status or environmental status scores. Acta Neurol Scand 1984;70:Suppl 101:87-91.

18 Donaldson SW, Wagner CC, Gresham GE. A unified ADL evaluation form. Arch Phys Med Rehabil 1973;54:175-9.

19 Gresham GE, Phillips TF, Labi MLC. ADL status in stroke: relative merits of three standard indexes. Arch Phys Med Rehabil 1980;61:355-8.

20 Wylie CM, White BK. A measure of disability. Arch Environ Health 1964;8:834-9.

21 Skilbeck CE, Wade DT, Langton Hewer R, Wood VA. Recovery after stroke. J Neurol Neurosurg Psychiatry 1983;46:5-8.

22 Katz S, Ford AB, Moskowitz RW, Jackson BA, Jaffe MW. Studies of illness in the aged. The index of ADL: a standardised measure of biological and psychosocial function. JAMA 1963;185:914-9.

23 Wade DT, Wood VA, Langton Hewer R. Recovery after stroke: the first three months. J Neurol Neurosurg Psychiatry 1985;48:7-13.

24 Prescott RJ, Garraway WM, Akhtar AJ. Predicting fucntional outcome following acute stroke using a standard clinical examination. Stroke 1982;13:641-7.

25 Wade DT, Skilbeck CE, Langton Hewer R. Predicting Barthel ADL score at 6 months after an acute stroke. Arch Phys Med Rehabil 1983;64:24-8.

26 Wade DT, Langton Hewer R, Wood VA. Stroke: the influence of age upon outcome. Age Ageing 1984;13:357-67.

27 Lehmann JF, DeLateur BJ, Fowler RS, et al. Stroke rehabilitation: outcome and prediction. Arch Phys Med Rehabil 1975;56:383-9. 